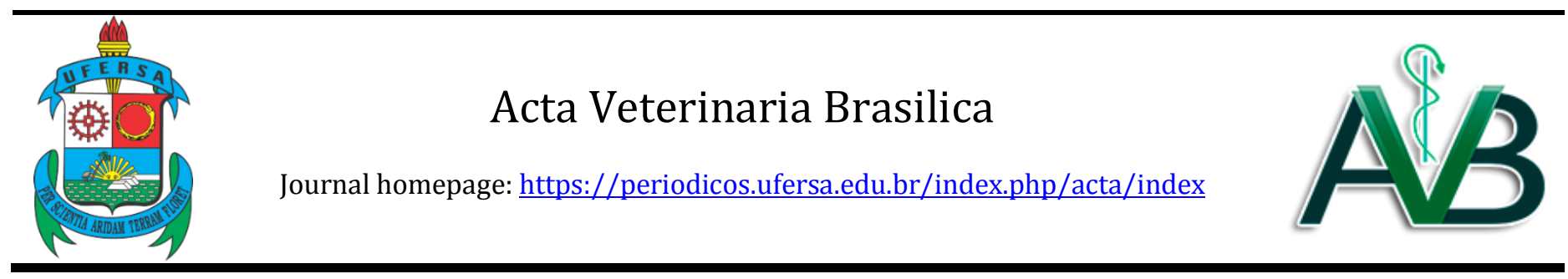

Original Article

\title{
Different dissociative anesthesia protocols for coatis (Nasua nasua)
}

Andresa de Cássia Martini1*, Samuel Monzem ${ }^{1}$, Lianna Ghisi Gomes ${ }^{1}$, Luiz Paulo Santos Vasconcelos ${ }^{2}$, Daniela Cristina Farias², Felipe Gomes da Silva³, Regina Célia Rodrigues da Paz ${ }^{4}$, Roberto Lopes Souza ${ }^{4}$, Luciana Dambrósio Guimarães ${ }^{4}$

${ }^{1}$ Graduate Program in Veterinary Sciences, Faculty of Veterinary Medicine, Federal University of Mato Grosso, Cuiabá, Brazil.

2Independent Veterinary Practices, Cuiabá, Brazil.

3Faculty of Agronomy and Animal Sciences, Federal University of Mato Grosso, Cuiabá, Brazil.

${ }^{4}$ Faculty of Veterinary Medicine, Federal University of Mato Grosso, Brazil.

\section{A R T I C L E I N F O}

\section{Article history}

Received 03 April 2017

Received in revised form 08 November 2017

Accepted 20 November 2017

\section{Keywords:}

Anesthetic

Dissociative drugs associations

Muscle relaxation

\begin{abstract}
A B S T R A C T
This study evaluated the effects of various combinations of dissociative drugs, tranquilizers, and sedatives in four male coatis (Nasua nasua) with an average age and weight of $4.8 \pm 1.3$ years and $6.02 \pm 0.56 \mathrm{~kg}$, respectively. We studied six groups with different anesthetic protocols: CX (10 mg/ kg ketamine-S and $2 \mathrm{mg} / \mathrm{kg}$ xylazine); CXA (10 mg/kg ketamine-S, $2 \mathrm{mg} / \mathrm{kg}$ xylazine, and $0.04 \mathrm{mg} / \mathrm{kg}$ atropine); CM $(10 \mathrm{mg} / \mathrm{kg}$ ketamine-S and $0.5 \mathrm{mg} / \mathrm{kg}$ midazolam); CMAc $(10 \mathrm{mg} / \mathrm{kg}$ ketamine-S, $0.5 \mathrm{mg} / \mathrm{kg}$ of midazolam, and $1 \mathrm{mg} / \mathrm{kg}$ acepromazine); C(20) M (20 mg/kg of ketamine-S and 0.5 $\mathrm{mg} / \mathrm{kg}$ midazolam); and TZ (7 mg/kg of tiletamine and zolazepam), with a 30-day interval between the completion of each procedure. We evaluated heart rate (HR), respiratory rate (RR), saturation of oxyhemoglobin (SpO2), body temperature $\mathrm{T}\left({ }^{\circ} \mathrm{C}\right)$, and muscle relaxation, using a scoring system. There was no statistical difference for Sp02. $\mathrm{T}\left({ }^{\circ} \mathrm{C}\right)$ was progressively reduced over time in all groups $(\mathrm{p}<0.0001)$. The groups $\mathrm{CM}, \mathrm{C}(20) \mathrm{M}, \mathrm{CMAc}$, and TZ demonstrated the greatest effect on $\mathrm{HR}$ and $\mathrm{T}\left({ }^{\circ} \mathrm{C}\right)$. With respect to respiratory rate reduction, groups $\mathrm{CM}$ and $\mathrm{TZ}$ showed similar results. The best degree of muscle relaxation was observed in groups CM and C(20)M. We concluded that the combination of $20 \mathrm{mg} / \mathrm{kg}$ ketamine and midazolam $0.5 \mathrm{mg} / \mathrm{kg}$ (group $\mathrm{C}(20) \mathrm{M}$ ) is an option for dissociative anesthesia of coatis, producing smaller changes in $\mathrm{T}\left({ }^{\circ} \mathrm{C}\right)$ and $\mathrm{HR}$, and promoting better muscular relaxation when compared to other combinations.
\end{abstract}

\section{INTRODUCTION}

Some wild species, such as coatis (Nasua nasua), have a high degree of adaptability to adverse conditions such as urban fragmented forests, which are becoming increasingly common throughout the world (MINTO et al., 2017). Chemical restraint in wild animals is necessary to undertake various clinical procedures such as surgery and laboratory analyses that may be needed at various times during the life of these animals. The anesthetic techniques must meet safety requirements related to both the animal and to the professional involved in the capture process and chemical restraint.
Anesthetic protocols in these species must be safe, have minimal effect on cardiorespiratory function, produce a quick and smooth recovery and induction, and have minimal effects on the animal in the long term (LARSEN et al., 2002; THORNTON et al., 2005).

Atropine is an anticholinergic used to prevent bradycardia, vagal tone-induced increased salivation, and excessive respiratory tract secretions (NATALINI, 2007).

Another class of drugs used for chemical restraint is fenotiazines. Acepromazine, a derivative fenotiazines,

\footnotetext{
* Corresponding author: andresa.martini@hotmail.com
} 
widely used in veterinary medicine, produces sedation, muscle relaxation, and has no analgesic effect. Its latency period is slow, but the sedation period is long, with a main side effect of lower blood pressure; thus, its use should be restricted to healthy animals (RANKIN, 2015).

Our objective was to evaluate the effects on the cardiorespiratory system and to describe the muscular relaxation obtained after administration of anesthetic drugs and the associations between dissociative tranquilizers or sedatives in coatis (Nasua nasua).

\section{MATERIALS AND METHODS}

This study was approved by the Committee of ethics in research animal CEUA Federal University of Mato Grosso, Campus Cuiabá, under the number 23108.002899/08-6.

\section{Animals}

We used four male coatis with an average age and weight of $4.8 \pm 1.3$ years and $6.02 \pm 0.56 \mathrm{Kg}$, respectively, from the Zoological Park of the Federal University of Mato Grosso, Campus Cuiabá. We conducted a clinical screening 30 days before the trial where the coatis were put on a food and water fast for 12 hours and then physically restrained with a type of sieve used in veterinary medicine for containment of animals. The animals were weighed on a digital scale after chemical restraint and were then clinically assessed. We collected blood from the external jugular vein for a $\mathrm{CBC}$, hemathozoaries and biochemistry. Fecal samples were obtained for parasitological examination. For every experiment, all animals remained housed in the same $250 \mathrm{~m}^{2}$ enclosure, with trees, logs, and stones to add environmental enrichment. The male coatis were separated from the females but were kept within visual and olfactory range. The animals were fed daily with fruit, fish or meat, commercial dog food, and one egg. Water was available ad libitum, and during the trial period, all animals received vitamins and mineral supplements added to their daily food.

\section{Experimentation}

Each animal was subjected to anesthesia with 6 different anesthetic protocols, with a 30-day interval between each procedure. After the pre-anesthetic preparation consisting of 12 hours of fasting, the animals were captured in their enclosures with a puçá and properly restrained for intramuscular administration of the anesthetics. The following anesthetic protocols were employed for six groups: CX Group (10 mg/kg ketamine$\mathrm{S}$ and $2 \mathrm{mg} / \mathrm{kg}$ xylazine), CXA Group $(10 \mathrm{mg} / \mathrm{kg}$ ketamine-S, $2 \mathrm{mg} / \mathrm{kg}$ xylazine, and $0.04 \mathrm{mg} / \mathrm{kg}$ atropine), CM Group $(10 \mathrm{mg} / \mathrm{kg}$ ketamine-S and $0.5 \mathrm{mg} / \mathrm{kg}$ midazolam), CMAc Group (10 mg/kg ketamine-S, 0.5 $\mathrm{mg} / \mathrm{kg}$ of midazolam, and $1 \mathrm{mg} / \mathrm{kg}$ acepromazine),
C(20)M Group (20 mg/kg of ketamine-S and $0.5 \mathrm{mg} / \mathrm{kg}$ midazolam), and TZ Group (7 $\mathrm{mg} / \mathrm{kg}$ of tiletamine and zolazepam).

The applied doses were calculated using the weight determined in the previous month from the first clinical evaluation. To account for weight variations within the previous 30 days, the animals were weighed again immediately after anesthetic induction to determine the actual dose of medication administered. The animals were then transported from their environment to an outpatient clinic where we proceeded to take blood from the jugular vein for a second hematological and biochemical analysis. The coatis were kept in the right lateral decubitus during the anesthetic maintenance period, and during the recovery period, they were placed in appropriate cages of $1 \mathrm{~m} \times 60 \mathrm{~cm} \times 60 \mathrm{~cm}$ until recovery was complete.

We evaluated the following parameters: oxyhemoglobin saturation (Sp02) via pulse oximetry; heart rate through electrocardiography (ECG ® PC, TEB Electronic Brazilian Technology Ltda., São Paulo, Brazil), DII and $50 \mathrm{~mm} / \mathrm{s}$ according to standard techniques for small animals; respiratory rate $(R R)$, determined by viewing the movement of the rib cage; body temperature $\mathrm{T}\left({ }^{\circ} \mathrm{C}\right)$ with a digital thermometer, positioned in the anus of the animal; and muscle relaxation based on the flexural strength of the limbs, mandibular tone, and observation of induced muscle activity, according to a scoring system (1: intense, 2: regular, 3: light, and 4: missing) and always by the same recorded evaluator. The variables were measured 5 minutes after the latency period and every 10 minutes during the anesthetic maintenance period (M10 to M40).

All data were analyzed by the SAS program University Edition, which provided descriptive statistics, both general and specific to the treatments, Pearson correlations (variables with normal distribution), and Spearman (variables with ranked values). The program also provided an ANOVA result, depending on the treatment and effect on the animal, as well as the covariate time, when applicable. Subsequently, we tested normality (Kolmogorov-Smirnov test), and variables with a normal residual distribution were subject to interpretation. The other variables underwent a procedure to remove outliers and, if necessary, data transformation. We then repeated the ANOVAS and normality test results, interpreting the variables that met the assumption of normality. The remaining variables were subjected to a nonparametric test containing blocks, using the Friedman's procedure, and the results were interpreted. We used the Tukey test $(p<0.05)$ to compare the averages for the times and groups.

\section{RESULTS AND DISCUSSION}

From the ECG data, sinus arrhythmia was observed in Group CX at M20 (20 minutes into anesthesia) and at 
M30 in 50\% of the animals (2/4), and at M40 in 100\% (4/4). In Group CM, sinus arrhythmia was detected at M40 in 25\% (1/4) of the animals and in 25\% (1/4) of Group TZ at M30. A normal sinus rhythm was detected in $100 \%(4 / 4)$ of the animals in groups C(20)M, CMAc, and CXA. Ferri et al. (2008) reported that coatis (Nasua nasua) anesthetized with ketamine $(10 \mathrm{mg} / \mathrm{kg})$ and xylazine $(2 \mathrm{mg} / \mathrm{kg}$ ) developed sinus arrhythmia with a wandering pacemaker in $9.52 \%$ of the animals. There is no information on the heart rate of unanesthetized coatis, but in this study, we believe that the observed arrhythmias were caused by xylazine, since this was observed at almost all times, while in the other groups, the observation was sporadic. Larger studies must be conducted to better characterize and standardize eletrocardiograficamente for coatis that are minimally affected by sedatives or anesthetic drugs.

There was a gradual reduction of HR, at a rate of 1 beat every 2 minutes, between recording times in the groups. The HR was greatest in the CMAc, C(20)M, CM, and TZ groups, intermediate in the CXA group, and lowest $(102$ \pm 6.72 , Table 1 ) in the CX group. Xylazine may cause bradycardia, sinoatrial block, first and second degree atrioventricular block, atrioventricular dissociation, and sinus arrhythmia, according to Hall and Clarke (1987), which may explain the drop in HR for the groups associated with xylazine. According to Paddleford (2001) and Lemke (2007), this change is caused by increased vagal tone and baroreceptor reflex and can be minimized by the sympathomimetic effect of ketamine.

Table 1 - Influence of different protocols of dissociative anesthesia on heart rate (HR), respiratory rate (RR), oxyhemoglobin saturation ( $\mathrm{SpO} 2)$, and temperature $\left(\mathrm{T}^{\circ} \mathrm{C}\right.$ ) in coatis (Nasua nasua). Mean values and standard error of the variables were obtained at 10, 20, 30, and 40 minutes of anesthesia (M10, M20, M30, and M40) and between groups.

\begin{tabular}{|c|c|c|c|c|c|}
\hline Variable & Group & Minimum & Average & Maximum & p. Value $<$ \\
\hline \multirow{6}{*}{ HR (beats/minute) } & $\mathrm{CX}$ & 63 & $102 \pm 6.72^{\mathrm{c}+}$ & 160 & 0.0001 \\
\hline & CXA & 70 & $131 \pm 5.80^{\mathrm{b}+}$ & 168 & 0.0001 \\
\hline & $\mathrm{CM}$ & 181 & $216 \pm 5.43^{\underline{a}+}$ & 254 & 0.0001 \\
\hline & CMAc & 171 & $223 \pm 5.71 \underline{a}_{+}$ & 254 & 0.0001 \\
\hline & $\mathrm{C}(20) \mathrm{M}$ & 186 & $224 \pm 4.58^{\underline{a}+}$ & 250 & 0.0001 \\
\hline & $\mathrm{TZ}$ & 109 & $198 \pm 11.82^{\mathrm{a}_{+}}$ & 252 & 0.0001 \\
\hline \multirow[t]{6}{*}{$R R$ (movements/minute) } & $\mathrm{CX}$ & 24 & $45 \pm 3.17 \mathrm{c}$ & 72 & 0.0005 \\
\hline & CXA & 28 & $42 \pm 4.91^{b, c}$ & 96 & 0.0005 \\
\hline & $\mathrm{CM}$ & 28 & $57 \pm 6.70^{\mathrm{a}}$ & 136 & 0.0005 \\
\hline & CMAc & 28 & $36 \pm 2.18^{b, c}$ & 60 & 0.0005 \\
\hline & $\mathrm{C}(20) \mathrm{M}$ & 20 & $32 \pm 2.97 c$ & 72 & 0.0005 \\
\hline & $\mathrm{TZ}$ & 20 & $41 \pm 3.90^{\mathrm{a}, \mathrm{b}, \mathrm{c}}$ & 64 & 0.0005 \\
\hline \multirow[t]{6}{*}{$\mathrm{SpO}_{2}$} & $\mathrm{CX}$ & 81 & $93 \pm 1.45^{\underline{a}}$ & 99 & 0.0171 \\
\hline & CXA & 81 & $91 \pm 1.22^{\underline{a}}$ & 98 & 0.0171 \\
\hline & $\mathrm{CM}$ & 88 & $94 \pm 0.76^{a}$ & 98 & 0.0171 \\
\hline & CMAc & 89 & $96 \pm 0.81^{\underline{a}}$ & 99 & 0.0171 \\
\hline & $\mathrm{C}(20) \mathrm{M}$ & 89 & $92 \pm 0.85^{\underline{a}}$ & 97 & 0.0171 \\
\hline & $\mathrm{TZ}$ & 86 & $92 \pm 0.93^{\underline{a}}$ & 99 & 0.0171 \\
\hline \multirow[t]{6}{*}{$\mathrm{T}\left(\stackrel{o}{ }^{\mathrm{C}} \mathrm{C}\right)$} & $\mathrm{CX}$ & 34 & $37 \pm 0.42^{\mathrm{b}+}$ & 40 & 0.0001 \\
\hline & CXA & 37 & $38 \pm 0.17^{a+}$ & 39 & 0.0001 \\
\hline & $\mathrm{CM}$ & 36 & $38 \pm 0.19 \underline{a}, \mathrm{~b}+$ & 39 & 0.0001 \\
\hline & CMAc & 38 & $38 \pm 0.11^{\mathrm{a}+}$ & 39 & 0.0001 \\
\hline & $\mathrm{C}(20) \mathrm{M}$ & 37 & $38 \pm 0.09^{a+}$ & 39 & 0.0001 \\
\hline & $\mathrm{TZ}$ & 36 & $38 \pm 0.17^{a+}$ & 39 & 0.0001 \\
\hline \multirow[t]{6}{*}{ Relaxation } & $\mathrm{CX}$ & 1 & $2 \pm c$ & 3 & 0.0001 \\
\hline & CXA & 1 & $1 \pm^{c}$ & 2 & 0.0001 \\
\hline & $\mathrm{CM}$ & 1 & $2 \pm \underline{a}$ & 3 & 0.0001 \\
\hline & CMAc & 1 & $1 \pm c$ & 3 & 0.0001 \\
\hline & $\mathrm{C}(20) \mathrm{M}$ & 1 & $2 \pm \underline{a}$ & 3 & 0.0001 \\
\hline & $\mathrm{TZ}$ & 1 & $2 \pm b$ & 4 & 0.0001 \\
\hline
\end{tabular}

Anesthetic protocols: ketamine and midazolam (CM); xylazine, ketamine, and atropine (CXA); tiletamine and zolazepam (TZ); ketamine, midazolam, and acepromazine (CMAc); ketamine $(20 \mathrm{mg} / \mathrm{kg})$ and midazolam (C(20)M), and ketamine and xylazine (CX).

$\mathrm{a}, \mathrm{b}, \mathrm{c}$ Medium followed by lowercase letters exhibit significant difference compared to the other groups ( $\mathrm{p}<0.05)$.

+ Medium followed by the symbol present significant difference in relation to time $(<\mathrm{p} 0.05)$. 
Lemke (2007) reports that the administration of an anticholinergic commonly causes decreased vagal tone, with consequent sinus tachycardia and increased cardiac output, without significant changes in blood pressure. In this study, we found significant effects of atropine in the CXA group compared to the CX group, corroborating Paddleford (2001), who described how atropine can increase HR.

The effects of combining midazolam with a higher dose of ketamine-S (20 mg/kg) in coatis (Nasua nasua) were observed by Gregores (2006), in which the HR remained constant at $218.70 \pm 30.70$ beats per minute, a result similar to groups CM and C(20)M, where an HR of $216 \pm$ 5.43 and $224 \pm 4.58$ was observed, respectively (Table 1). In our study, even with the sympathomimetic dosedependent effects of ketamine, no statistical difference was observed with the two doses used.

Paddleford (2001) described how the association of ketamine and acepromazine affects HR variables. The addition of acepromazine to the midazolam and ketamine protocol did not produce an increase in HR as compared to use of midazolam and ketamine in the same doses; these findings agree with those of Atalan et al. (2002), who stated that this variable changed minimally. However, according to Lemke (2007), high doses of acepromazine $(1 \mathrm{mg} / \mathrm{kg})$ can cause sinus bradycardia and atrioventricular block in pets, but this was not observed in our study using a similar dose.

No significant differences were observed in $\mathrm{SpO} 2$ between the groups or time periods. Almeida et al. (2000) stated that the combination of tiletamine/zolazepam in dogs (Canis familiaris) pretreated with acepromazine did not significantly change the saturation of oxygen in hemoglobin. Cistola et al. (2004) observed changes in cats anesthetized with ketamine, xylazine, tiletamine, and zolazepam and reported that alpha-2-adrenergic agonists like xylazine cause intense vasoconstriction and reduced blood flow to many organs. This results in low saturation, which can lead to technical problems in signal detection, since obtaining a pulse signal very reliably is not always possible. However, this fault was not detected in our study.

Regarding the respiratory system, groups $\mathrm{CM}, \mathrm{CX}$, and TZ demonstrated statistical similarity with respect to respiratory rate, disagreeing with Cruz et al. (1998) who observed the effects of both ketamine $(15 \mathrm{mg} / \mathrm{kg})$ and xylazine ( $\mathrm{l} \mathrm{mg} / \mathrm{kg})$, and ketamine $(15 \mathrm{mg} / \mathrm{kg})$ and midazolam $(0.5 \mathrm{mg} / \mathrm{kg})$ in Capybaras (Hydrochoerus hydrochaeris, Linnaeus), administered by intramuscular injection. In that study, the first combination had less of an effect on RR than the second. In addition, Furtado et al. (2010) found similar results in monkeys of the genus Callithrix, reporting a decrease of RR with similar doses of ketamine and midazolam. The decrease in RR in their study may be related to properties of benzodiazepines as a tranquilizer, sedative, hypnotic, anticonvulsant, and a muscle relaxant.

Temperature $\mathrm{T}\left({ }^{\circ} \mathrm{C}\right)$ was found to decrease progressively by $0.04^{\circ} \mathrm{C}$ per minute between each recording time for all groups. A comparison between groups showed that the lowest temperatures were observed in groups CM and CX. Our findings agreed with those of Cruz et al. (1998), who observed a reduction in $\mathrm{T}\left({ }^{\circ} \mathrm{C}\right)$ in all groups when comparing the association of ketamine with xylazine and ketamine with midazolam in Capybaras. According to Tracy (1988), the combination of tiletamine and zolazepam has a depressant effect on body temperature in dogs, which explains the decrease of temperature for the TZ Group between time periods in this study. However, Haskins; Farver; Patz (1985) attributed an increase in body temperature to muscular activity when ketamine is used alone, justifying the reduction found in our study by this association.

In terms of muscle relaxation, there was a variation in the scores between the groups. While statistical similarity was observed, we noted greater relaxation in the $\mathrm{CM}$ and $\mathrm{C}(20) \mathrm{M}$ groups, intermediate relaxation in the TZ group, and less of an effect for the CXA, CMAc, and CX groups. These findings disagree with those of Evans (2005) and Telesco; Kneaded (2002), who reported that the alpha-2 receptor agonists-adrenergic receptors are often associated with ketamine in producing a synergistic effect and muscle relaxation.

\section{CONCLUSIONS}

The combination of ketamine $(20 \mathrm{mg} / \mathrm{kg})$ and midazolam $(0.5 \mathrm{mg} / \mathrm{kg}, \mathrm{C}(20) \mathrm{M})$ is an option for dissociative anesthesia of coatis, producing smaller changes in $\mathrm{T}\left({ }^{\circ} \mathrm{C}\right)$ and $\mathrm{HR}$, and promoting better muscular relaxation when compared to other combinations that promoted greater variations in parameters evaluated.

\section{ACKNOWLEDGEMENTS}

Thanks to the direction and the employees of the Zoological Park of the Federal University of Mato Grosso and the Foundation of Support to the Research of the State of Mato Grosso.

\section{REFERENCES}

ALMEIDA, E. M. P. et al. Efeitos cardiorrespiratórios da associação de tiletamina/zolazepam em cães (Canis familiaris) pré-tratados ou não pela acepromazina. (Cardiorespiratory effects of tiletamine/zolazepam in dogs (Canis familiaris) given acepromazin). Brazilian Journal of Veterinary Research and Animal Science, v. 37, n. 3, p.00-00, 2000.

ATALAN, G. et al. Comparison of xylazine + ketamine-HCl anaesthetic agents with acepromazine + butorphanol + ketamine combinations for their clinical and cardiorespiratory effects in dogs. Veteriner Cerrahi Dergisi, v. 8, n. 3-4, p. 35-40, 2002. 
CISTOLA, A. M. et al. Anesthetic and psysiologic effects of tiletamine, zolazepam, ketamine, and xylazine combination (TKX) in feral cats indergoing surgical sterilization. Journal of Feline Medicine and Surgery, v. 6, p. 297-303, 2004.

CRUZ, M. L et al. Técnicas anestésicas injetáveis em capivaras (Hydrochoerus hydrochaeris, Linné). (Anaesthetic techniques in capybaras (Hydrochoerus hydrochaeris, Linné). Ciência Rural, v. 28, p. 411-415, 1998

EVANS, R.H. Anestesia y contención de Mapaches y otros miembros de su familia (Carnivora, Procyonidae). Internacional Veterinary Information Service, n 22, 2005.

FERRI, R. C. et al. Eletrocardiografia em quatis (Nasua nasua Linnaeus, 1766) mantidos em cativeiro e contidos quimicamente com quetamina e xilazina. (Electrocardiography in coatis (Nasua nasua - Linnaeus, 1766) maintained in captivity and contained chemically with ketamine and xylazine). Clínica Veterinária, Ano XIII, n. 74, 2008.

FURTADO, M.M. et al. Comparison of racemic ketamine versus (s+) ketamine when combined with midazolam for anesthesia of Callithrix jacchus and Callithrix penicillata. Journal of Zoo Wildlife Medicine, v. 41, p. 389-394, 2010

GREGORES, G. B. Topografia vértebro-medular e anesthesia espinhal em quati (Nasua nasua). 2006. 70f. Dissertação de mestrado e Medicina Veterinária - Curso de Pós-graduação em Anatomia dos Animais Domésticos e Silvestres, Universidade de São Paulo, São Paulo.

HALL, L. W.; CLARKE, K. W. Anestesia Veterinária. 8ª̣ed. São Paulo: Manole LTDA, 1987. 451p.

HASKINS, S. C.; FARVER, T. M.; PATZ, J. D. Ketamine in dogs. American Journal of Veterinary Research, v. 46, p.1855-1860, 1985.
LARSEN, R. S. et al. Cardiorrespiratory effects of medetomidinebutorphanol, medetomidine-butorphanol-dizepam, and metedomidinebutorphanol-ketamine in captive red wolfes (Canis rufus). Journal of Zoo and Wildlife Medicine, v. 33, n. 2, p. 101-107, 2002.

LEMKE, K. A. Anticholinergics and sedatives. In: TRANQUILLI, W.J.; THURMAN, J.C.; GRIM, K. Lumb \& Jone's Veterinary anesthesia and analgesia. 4ed. Ames: Blackwell, 2007, p. 203-240.

MINTO, B. W. et al. Minimally invasive hysterectomy in Coatis (Nasua nasua). Pesquisa Veterinária Brasileira, v.37, n. 6, p.627-629, 2017.

NATALINI, C.C. Teoria e Técnicas em Anestesiologia Veterinária Porto Alegre: Artmed, 2007.

PADDLEFORD, R.R. Drogas Anestésicas. In: PADDLEFORD, R.R. Manual de Anestesia em Pequenos Animais. 2ed. São Paulo: Roca, 2001. Cap. 3, p. 37-88.

RANKIN, D.C. Sedatives and tranquilizers. In: GRIMM, K.A.; LAMONT, L.A.; TRANQUILLI, W.J.; GREENE, S.A.; ROBERTSON, S.A. (Eds). Veterinary Anesthesia and Analgesia. $5^{\text {th }}$ Ed. Wiley Blackwell : Iowa, 2015. Cap. 10, p. $196-206$.

TELESCO, R. L.; SOVADA M. A. Immobilization of swift foxes with ketamine hydrochloride-xylazine- hydrochloride. Journal Wildlife Diseases, v. 38, n 4, p. 764-768, 2002.

THORNTON, P. D. et al. Preliminary comparison of four anaesthetic techniques in badgers (Meles meles). Veterinary Anaesthesia and Analgesia, v. 32, p. 40-47, 2005.

TRACY, C. $\mathrm{H}$ et al. Comparing the effects of intravenous and intramuscular administration of Telazol. Veterinary Medicine, v. 83, n. 1, p. 104-11, 1988. 